\title{
A hybrid of fuzzy FMEA-AHP to determine factors affecting alternator failure causes
}

\author{
Reza Kiani Aslani ${ }^{\mathrm{a}}$, Hamid Reza Feili ${ }^{\mathrm{b}^{*}}$ and Hassan Javanshir ${ }^{\mathrm{c}}$
}

${ }^{a}$ Department of Industrial Engineering, Najafabad Branch, Islamic Azad University, Isfahan, Iran

${ }^{b}$ Department of Industrial Engineering, Karaj Branch, Islamic Azad University, Alborz, Iran

${ }^{c}$ Department of Industrial Engineering, South Tehran Branch, Islamic Azad University, Tehran, Iran

C H R O N I C L E

Article history:

Received January 20, 2014

Accepted 5 July 2014

Available online

August 202014

FMEA

AHP

Alternator failure

Optimal weight

\section{A B S T R A C T}

This paper presents a method to determine factors influencing alternator failure causes. Failure Mode and Effects Analysis (FMEA) is one of the first systematic techniques for failure analysis based on three factors including Probability (P), Severity (S) and Detection (D). Traditional FMEA method considers equal weights for all three factors, however, in read-world cases; one may wish to consider various weights. The proposed study develops a mathematical model to determine optimal weights based on analytical hierarchy process technique. The implementation of the proposed study has been demonstrated for a read-world case study of alternator failure causes.

\section{Introduction}

Failure Mode and Effects Analysis (FMEA) is one of the first systematic techniques for failure analysis based on three factors including Probability (P), Severity (S) and Detection (D). There are literally many applications of FMEA method in various areas (Rawat \& Wang, 2005). DominguezGarcia et al. (2006), for instance, introduced a method for the dependability analysis of new automotive safety-relevant systems. By introduction of safety-relevant electronic systems in cars, it is essential to carry out a thorough dependability analysis of those systems to fully understand and quantify the failure mechanisms to make the necessary improvement in the design. They used various system level FMEAs to determine various failure modes of the system and used a Markov model to quantify their probability of occurrence. Parrott et al. (2011) applied advanced FMEA techniques to vehicle fire cause determinations. Kulkarni (2013) successfully regained lost market through application of FMEA tool to revamp design of single phase induction motor. Tsang and Ho (2002) presented an application of reliability-centered maintenance technology on electric trains.

*Corresponding author. Tel: +989123108647

E-mail addresses: hrfeili@gmail.com (H.R. Feili)

(c) 2014 Growing Science Ltd. All rights reserved. doi: $10.5267 /$ j.ms 1.2014.8.024 


\section{The proposed study}

This paper presents a method to determine factors influencing alternator failure causes. Failure Mode and Effects Analysis (FMEA) is one of the first systematic techniques for failure analysis based on three factors including Probability (P), Severity (S) and Detection (D).

\subsection{Probability}

It is always essential to look at the cause of a failure mode and the likelihood of occurrence, which could be accomplished by analysis, calculations /FEM, looking at similar items or processes and the failure modes documented for them previously. A failure cause is normally considered as a design weakness and all potential causes for a failure mode such as human errors in handling, fatigue, etc. ought to be determined.

\subsection{Severity}

This item determines the severity for the worst-case scenario adverse end effect. It is a good idea to write these effects down in terms of what the user could see or experience in terms of functional failures. Each end effect is given a Severity number (S) from, say, I (no effect) to VI (catastrophic), based on cost and/or loss of life or quality of life.

\subsection{Detection}

Detection is the technique by which a failure is detected, isolated by operator and/or maintainer and the time it may take. This is essential for maintainability control and is important for multiple failure scenarios. It is necessary to make it clear on how the failure mode or cause could be discovered by an operator under normal system operation.

\subsection{Risk}

In FMEA technique, Risk is the combination of End Effect Probability $(\mathrm{P} \times \mathrm{S})$ And Severity (D) where probability and severity incorporates the impact on non-detectability. This may affect the end effect probability of failure or the worst case impact Severity.

\subsection{Weighting technique}

Traditional FMEA method considers equal weights for all three factors, however, in read-world cases; one may wish to consider various weights as follows,

$R P N=W_{S} \times S+W_{O} \times O+W_{D} \times D$

where $W_{s}, W_{o}$ and $W_{D}$ are relative weights of $S, O$ and $D$, respectively. The proposed study of this paper determines the weights using the method developed by Wang et al. (2006) as follows,

$\min Z=\sum_{i=1}^{n} \sum_{j=1, j \neq i}^{n}\left(\left(\ln w_{\mathrm{i}}^{\mathrm{L}}-\ln \mathrm{w}_{\mathrm{j}}^{\mathrm{U}}-\ln \mathrm{L}_{\mathrm{ij}}\right)^{2}+\left(\ln \mathrm{w}_{\mathrm{i}}^{\mathrm{M}}-\ln \mathrm{w}_{\mathrm{j}}^{\mathrm{M}}-\ln \mathrm{M}_{\mathrm{ij}}\right)^{2}+\left(\ln \mathrm{w}_{\mathrm{i}}^{\mathrm{U}}-\ln \mathrm{w}_{\mathrm{j}}^{\mathrm{L}}-\ln \mathrm{U}_{\mathrm{ij}}\right)^{2}\right)$

subject to

$W_{i}^{L}+\sum_{j=1, j \neq i}^{n} W_{j}^{U} \geq 1$

$W_{i}^{U}+\sum_{j=1, j \neq i}^{n} W_{j}^{L} \leq 1$

$\sum_{i=1}^{n} W_{i}^{M}=1 \quad \mathrm{i}=1,2, \ldots \ldots, \mathrm{n}$

$\sum\left(W_{i}^{L}+W_{i}^{U}\right)=2$

$W_{i}^{U} \geq W_{i}^{M} \geq W_{i}^{L} \geq 0$

where $W_{i}^{U}, W_{i}^{M}$ and $W_{i}^{L}$ are associated with fuzzy triangular numbers assigned to each item to handle uncertainty. 


\section{The case study}

The case study of this paper is associated with determining factors influencing alternator failure causes. Decision makers have given the following triangular numbers for three factors of S, O and D summarized in Table 1 as follows,

Table 1

The summary of triangular numbers

\begin{tabular}{ccccc}
\hline & $\mathrm{S}$ & $\mathrm{O}$ & $\mathrm{D}$ & Relative weight \\
\hline $\mathrm{S}$ & $(1,1,1)$ & $(4,5,6)$ & $(4,5,6)$ & $(0.674,0.701,0.715)$ \\
$\mathrm{O}$ & $\left(\frac{1}{6}, \frac{1}{5}, \frac{1}{4}\right)$ & $(1,1,1)$ & $(2,3,4)$ & $(0.169,0.202,0.238)$ \\
$\mathrm{D}$ & $\left(\frac{1}{6}, \frac{1}{5}, \frac{1}{4}\right)$ & $\left(\frac{1}{4}, \frac{1}{3}, \frac{1}{2}\right)$ & $(1,1,1)$ & $(0.084,0.097,0.119)$ \\
\hline
\end{tabular}

In Table 1, the relative weights are calculated based on fuzzy analytical hierarchy process (Chang, 1996). Table 2 demonstrates the summary of the factors gathered from decision makers.

\section{Table 2}

The summary of factors associated with alternator failure along with fuzzy

\begin{tabular}{|c|c|c|c|c|c|c|c|c|c|c|c|c|c|c|c|}
\hline Item & Factors & & $\mathrm{S}$ & & & $\mathrm{O}$ & & & $\mathrm{D}$ & & & RPN & & Defuzzy & Rank \\
\hline 1 & Limp and tolerance levels & 5 & 6 & 7 & 2 & 3 & 4 & 5 & 6 & 7 & 50 & 108 & 196 & 113 & 7 \\
\hline 2 & Failure in the alternator assembly devise & 6 & 7 & 8 & 4 & 5 & 6 & 2 & 3 & 4 & 48 & 105 & 192 & 110 & 8 \\
\hline 3 & Bearing failure & 6 & 7 & 8 & 3 & 4 & 5 & 3 & 4 & 5 & 54 & 112 & 200 & 117 & 6 \\
\hline 4 & Conflict between rotor and stator & 7 & 8 & 9 & 5 & 6 & 7 & 3 & 4 & 5 & 105 & 192 & 315 & 198 & 5 \\
\hline 5 & Electromagnetic noise & 3 & 4 & 5 & 6 & 7 & 8 & 6 & 7 & 8 & 108 & 196 & 320 & 202 & 3 \\
\hline 6 & Aerodynamic noise & 4 & 5 & 6 & 5 & 6 & 7 & 6 & 7 & 8 & 120 & 210 & 336 & 216 & 1 \\
\hline 7 & Electrical leakage stator & 7 & 8 & 9 & 4 & 5 & 6 & 4 & 5 & 6 & 112 & 200 & 324 & 206 & 2 \\
\hline 8 & Electrical leakage of rotor & 6 & 7 & 8 & 5 & 6 & 7 & 4 & 5 & 6 & 120 & 210 & 336 & 216 & 1 \\
\hline 9 & Lack of proper regulation voltage & 6 & 7 & 8 & 3 & 4 & 5 & 6 & 7 & 8 & 108 & 196 & 320 & 202 & 3 \\
\hline 10 & Corrosion of coal & 7 & 8 & 9 & 3 & 4 & 5 & 5 & 6 & 7 & 105 & 192 & 315 & 198 & 5 \\
\hline 11 & Rectifier of excitation system failure & 7 & 8 & 9 & 2 & 3 & 4 & 7 & 8 & 9 & 98 & 192 & 324 & 198.33 & 4 \\
\hline 12 & Rectifier of power system failure & 5 & 6 & 7 & 6 & 7 & 8 & 4 & 5 & 6 & 120 & 210 & 336 & 216 & 1 \\
\hline 13 & Failure to stimulate alternator on time & 2 & 3 & 4 & 1 & 2 & 3 & 7 & 8 & 9 & 14 & 48 & 108 & 52.333 & 9 \\
\hline 14 & The transmission system of power & 5 & 6 & 7 & 3 & 4 & 5 & 7 & 8 & 9 & 105 & 192 & 315 & 198 & 5 \\
\hline 15 & The transmission system of flow & 7 & 8 & 9 & 3 & 4 & 5 & 5 & 6 & 7 & 105 & 192 & 315 & 198 & 5 \\
\hline
\end{tabular}

Combining the information of Table 1 and Table 2 yields the final ranking based on the relative weights of the factors, which are summarized in Table 3 as follows,

Table 3

The results of final ranking

\begin{tabular}{|c|c|c|c|c|c|c|}
\hline Item & Factors & & RPN & & Defuzzy & Rank \\
\hline 1 & Limp and tolerance levels & 4.128 & 5.394 & 6.79 & 5.4373 & 12 \\
\hline 2 & Failure in the alternator assembly devise & 4.888 & 6.208 & 7.624 & 6.24 & 7 \\
\hline 3 & Bearing failure & 4.803 & 6.103 & 7.505 & 6.137 & 9 \\
\hline 4 & Conflict between rotor and stator & 5.815 & 7.208 & 8.696 & 7.2397 & 1 \\
\hline 5 & Electromagnetic noise & 3.54 & 4.894 & 6.431 & 4.956 & 13 \\
\hline 6 & Aerodynamic noise & 4.045 & 5.396 & 6.908 & 5.4497 & 11 \\
\hline 7 & Electrical leakage stator & 5.73 & 7.103 & 8.577 & 7.1367 & 2 \\
\hline 8 & Electrical leakage of rotor & 5.225 & 6.604 & 8.1 & 6.643 & 5 \\
\hline 9 & Lack of proper regulation voltage & 5.055 & 6.397 & 7.862 & 6.437 & 6 \\
\hline 10 & Corrosion of coal & 5.645 & 6.998 & 8.458 & 7.0337 & 3 \\
\hline 11 & Rectifier of excitation system failure & 5.644 & 6.99 & 8.458 & 7.0307 & 4 \\
\hline 12 & Rectifier of power system failure & 4.72 & 6.105 & 7.623 & 6.1493 & 8 \\
\hline 13 & Failure to stimulate alternator on time & 2.105 & 3.283 & 4.645 & 3.3443 & 14 \\
\hline 14 & The transmission system of power & 4.465 & 5.79 & 7.266 & 5.8403 & 10 \\
\hline 15 & The transmission system of flow & 5.645 & 6.998 & 8.458 & 7.0337 & 3 \\
\hline
\end{tabular}

\section{Discussion and conclusion}

The results of Table 3 indicate that conflict between rotor and stator is number one priority for detecting any failure followed by electrical leakage of stator, corrosion of coal, the transmission 
system, rectifier excitation system failure and electrical leakage of rotor. The proposed fuzzy FMEA of this paper has enabled us to assign weight for each of three items in FMEA model. This is an advantage because we used analytical hierarchy process to rank the factors. There are also other opportunities for ranking three factors based on other multi criteria decision making techniques and we leave it for interested researchers as future studies.

\section{Acknowledgement}

The authors would like to thank the anonymous referees for constructive comments on earlier version of this paper.

\section{References}

Chang, D. Y. (1996). Applications of the extent analysis method on fuzzy AHP. European Journal of Operational Research, 95(3), 649-655.

Dominguez-Garcia, A. D., Kassakian, J. G., \& Schindall, J. E. (2006). Reliability evaluation of the power supply of an electrical power net for safety-relevant applications. Reliability Engineering \& System Safety, 91(5), 505-514.

Kulkarni, G. (2013). Successfully regained lost market through application of FMEA tool to revamp design of single phase induction motor. Journal of Business Administration Research, 2(2), p31.

Parrott, K. D., Mattes, P. J., \& Stahl, D. R. (2011, January). Applying advanced FMEA methods to vehicle fire cause determinations. In ASME 2011 International Mechanical Engineering Congress and Exposition (pp. 621-631). American Society of Mechanical Engineers.

Rawat, A., \& Wang, J. (2005). A reliability strategy for zero field failures in automotive electronics (No. 2005-01-1398). SAE Technical Paper.

Tsang, H. L., \& Ho, T. K. (2002, July). Application of reliability-centred maintenance technology on electric trains. In Proceedings of the Conference on Traffic and Transportation Studies, ICTTS (p. X1208).

Wang, Y. M., Elhag, T., \& Hua, Z. (2006). A modified fuzzy logarithmic least squares method for fuzzy analytic hierarchy process. Fuzzy Sets and Systems, 157(23), 3055-3071. 